\title{
Non-root modals for the past and temporal shifting in Mandarin Chinese
}

Zhiguo Xie

\author{
Correspondence: xie.251@osu.edu \\ Department of East Asian \\ Languages and Literatures, The \\ Ohio State University, 360 Hagerty \\ Hall, 1775 College Road, Columbus, \\ $\mathrm{OH}$ 43210, USA
}

\begin{abstract}
This paper has two major goals. First, it provides a detailed empirical description of how the epistemic and metaphysical readings of the "non-root modal + Perf(ect) have" construction in English (e.g., John might have won the game yesterday) are expressed in Mandarin Chinese. The two readings both involve non-root modals for the past, i.e., non-root modals with either a past temporal perspective or a past temporal orientation. Certain languages express the two readings via manipulating the scope relation between the modal and the perfect aspect. In this paper, I show that Mandarin Chinese, by contrast, resorts to the presence/absence of such aspectual adverbs as 仍 reng 'still' and 还 hai 'still', to determine the reading of non-root modals for the past. Second, I propose that aspectual adverbs like reng and hai are operators that can back-shift the temporal perspective of a non-root modal from the speaker's utterance time to a past time. The back-shifting gives rise to a metaphysical reading of the non-root modal. In spite of surface differences, English and Mandarin Chinese actually employ similar strategies in expressing metaphysical modality with a past temporal perspective.

Keywords: Modality; Temporal shifting; Aspectual adverbs; Counterfactual implicature; Mandarin Chinese
\end{abstract}

\section{Background}

It is well-known that certain "non-root modal + Perf(ect) have" sentences in English are ambiguous between an epistemic reading and a metaphysical reading (Mondadori 1978, Condoravdi 2002). The former reading has to do with the belief state of an attitude holder (usually the speaker) about a past event; the latter reading has to do with the (developmental) potential of an event, given how history had transpired up to some past time. The sentence in 1 , for instance, illustrates the ambiguity:

(1) John might have won the game yesterday.

a. It is possible that John won the game yesterday.

b. The possibility for John to win the game existed yesterday.

The epistemic reading, roughly paraphrased in 1a, states that John winning the game yesterday is consistent with what the speaker believes at the utterance time. The metaphysical reading, roughly paraphrased in $1 \mathrm{~b}$, states that during (a contextually relevant sub-interval of) yesterday, it was possible for the world to develop in such a way that

(c) 2015 Xie; licensee Springer. This is an Open Access article distributed under the terms of the Creative Commons Attribution License (http://creativecommons.org/licenses/by/4.0), which permits unrestricted use, distribution, and reproduction in any medium, provided the original work is properly credited. 
John would win the game at a later time. In addition, the latter, metaphysical reading comes with a strong counterfactual implicature that John did not end up winning the game. Obviously, the two readings are different in terms of truth condition, and can be told apart explicitly by means of empirical tests. For example, the epistemic reading cannot be followed by an utterance by the same speaker that John actually did not win the game in the end. By contrast, the metaphysical reading is compatible with such an ensuing utterance by the same speaker. Moreover, the epistemic reading is compatible with, and actually often facilitated by, adding the word already after have; the metaphysical reading can be made easier to process by adding still before might (Condoravdi 2002).

More generally, the epistemic reading of English "non-root modal + Perf have" sentences involves the belief state of the speaker (or some other contextually relevant attitude holder) at the utterance time with regard to the happening (or not) of an event in the past relative to the speaker's utterance time. What is at stake for the epistemic reading is a (potential) past event perceived from the temporal perspective of the speaker's utterance time. Thus, the epistemic reading has a present temporal perspective and a past temporal orientation for the non-root modal ${ }^{\mathrm{a}}$. The metaphysical reading of the construction, by contrast, has to do with the potential of an event occurring in the future of some time; and this time is, in turn, located in the past of the speaker's utterance time. What is at stake for the metaphysical reading is the future evolution of the (potential) event, given how history had developed up to the relevant past time. Thus, the metaphysical reading has a past temporal perspective and a future temporal orientation (future with respect to the past perspective time) for the non-root modal. For the two readings, either the temporal perspective or the temporal orientation of the non-root modal is located in the past of the speaker's utterance time. In this paper, I will follow Condoravdi (2002) to simply call non-root modal expressions referring to the past "non-root modals for the past".

In addition, the metaphysical reading of non-root modals for the past generally comes with a strong counterfactual implicature (Condoravdi 2002). Although the event expressed by a "non-root modal + Perf have" sentence was metaphysically possible or necessary (depending on the quantificational force of the non-root modal) at the relevant past time, by using the metaphysical modal sentence the speaker implies that the metaphysical possibility or necessity did not materialize, and is no longer valid, at her utterance time. For the metaphysical reading of the sentence in 1, for example, although the possibility for John to win the game at some time future to yesterday existed during (the relevant sub-interval of) yesterday, by using the modal sentence, the speaker conveys that John did not actually win at her utterance time, and nor does the possibility for John to win the game hold any longer as of the utterance time.

Condoravdi (2002) treated the epistemic vs. metaphysical ambiguity of the "non-root modal + Perf have" construction in English as a case of scope ambiguity. In her analysis, the perfect aspectual particle have in the "non-root modal + Perf have" construction remains an aspectual auxiliary, rather than being a pure past tense operator. In the epistemic reading, the non-root modal takes wide scope over the perfect aspect, and in the metaphysical reading, the scope relation is exactly the reverse. For the English sentence John might have won:

(2) a. Epistemic reading: PRES (MIGHT (PERF (John win)))

b. Metaphysical reading: PRES (PERF (MIGHT (John win))) 
The temporal perspective of the non-root modal is determined by what immediately scopes over it. For the epistemic reading, because the modal scopes immediately under the outermost PRES(ent), it takes the speaker's utterance time, contributed by PRES, as the temporal perspective. At the same time, the modal scopes over the perfect aspect. The speaker's epistemic state is about a (potential) event at a past time perceived at the speaker's utterance time. By contrast, for the metaphysical reading, the perfect aspect scopes over the modal. Because the perfect aspect "has a back-shifting effect" (Condoravdi 2002: 66), it evaluates the temporal perspective of the modal to some time in the past of the speaker's utterance time. What is at stake is the happening (or not) of a (potential) event in the future of the temporal perspective, given how things have evolved up to this past time of evaluation.

An important empirical motivation and justification for Condoravdi's (2002) scope-based analysis of the ambiguity with the "non-root modal + Perf have" construction in English comes from languages like German and Italian, in which "the linear order between the perfect auxiliary and the modal in the syntax mirrors semantic scope" (Condoravdi 2002: 76). Abusch (2012), via Yun (2006), pointed out that Korean is another language that employs this scope-based strategy. Take the German sentences in 3 (adapted from Condoravdi 2002: ex. 38) for example. They each have one and only one reading. 3a has an epistemic reading, and is not compatible with modification by noch 'still'; $3 \mathrm{~b}$ has a metaphysical reading, and is not compatible with modification by schon 'already'.

(3) a. Er könnte ( $\sqrt{ }$ schon / "noch) gewonnen haben.

He could already / still won have

He might have (already/*still) won.

b. Er hätte ( $\sqrt{ }$ noch / *schon) gewinnen können.

He had still / already still / already could

He might (still/*already) have won.

Comparing the morpho-syntax of English with that of German, the fact that the "non-root modal + Perf have" construction in English is ambiguous between epistemic and metaphysical readings is most likely due to the impoverished morphology with modals in English. Except for the semi-modals have to and able to, there are no finite modals in English. By contrast, German has finite modals, and hence has the right apparatus to disambiguate the two readings overtly in syntax. For the epistemic sentence in 3a, the modal appears in the finite form and as the highest verb. For the metaphysical sentence in $3 \mathrm{~b}$, the modal appears in a non-finite form, which is embedded under a finite form of the perfect aspectual particle.

Regarding the counterfactual implicature observed with the metaphysical reading, Condoravdi (2002: 85) held that the metaphysical reading of the sentence in 1, without yesterday, is semantically equivalent to the metaphysical reading of the sentence in 4 , "except for the different temporal perspective of the modal":

(4) John might win the game.

Intuitively, metaphysical possibilities (or historical alternatives) diminish in numbers as the time passes. The metaphysical use of might has a past temporal perspective in 1 , 
and a present temporal perspective in 4 . Therefore, might in 1, ceteris paribus, quantifies over a wider domain of metaphysical possibilities than in 4. Furthermore, Condoravdi (2002) assumed that a common ground is the union of equivalence classes of worlds relative to THE SPEAKER'S UTTERANCE TIME. Under this assumption, she stipulated that the domain of metaphysical possibilities quantified by might in 1 is partly outside of the common ground. Thus, by using a scope reversal strategy to widen the domain of quantification of might, as Condoravdi (2002: 86) wrote:

the speaker indicates that the relevant state of affairs could not be verified in the common ground. In recovering the speaker's intention, the hearer can reason as follows: why would the speaker use an expression that requires backtracking in order to enlarge the domain of quantification, unless the speaker cannot take it for granted that the relevant state of affairs is verified in a domain that is a subset of the common ground? Therefore, the speaker must intend to communicate that this past possibility was an unactualized one.

With the above introduction as our background, let us now turn to non-root modals for the past in Mandarin Chinese. It is controversial (see Smith 1997, Lin 2006, Soh 2009, inter alia) whether Mandarin Chinese has a perfect aspectual particle comparable to English have or German haben. Even if we assume, as some scholars did (e.g., Li et al. 1982), that the sentential 了 $l e$ in Mandarin Chinese is a marker of the perfect aspect, it does not enter into a scope relation with non-root modals.

At this point, the attentive reader may point out that in certain varieties of Chinese, the existential/possessive verb 有you 'have' can be followed by a verb phrase and appears to behave like a perfect aspectual marker, as illustrated in 5. Even in those varieties, however, the aspectual use of you does not scopally interact with non-root modals to yield the ambiguity observed with the "non-root modal + Perf have" construction in English. The sentence in 6, for example, contains 可能 keneng 'may/might' before aspectual you and only has an epistemic reading, but not a metaphysical reading. If the positions of keneng and you are switched, you no longer can serve as a perfect aspectual marker: 有可能 you keneng is a lexicalized item that means 'there exists a possibility; it is possible'. The sentence in 7 cannot mean what 6 expresses, nor can it receive a metaphysical reading.

（5）他们都有买医疗保险。

tamen_dou_you_mai_yiliao__baoxian.

they_all_have_buy_medical_insurance

They all have bought health insurance.

（6）他们都可能有买医疗保险。

tamen_dou_keneng_you_mai_yiliao_baoxian.

they_all_possible_have_buy_medical_insurance

It is possible that they all have bought health insurance.

（7）他们都有可能买医疗保险。 tamen_dou_you_keneng_mai_yiliao_baoxian. they_all_have_possible_buy_medical_insurance They all may buy health insurance. 
In addition, I adopt the assumption that Mandarin Chinese does not have a finite/non-finite distinction (Xu 1986, Hu et al. 2001, but cf., Huang 1982). This lack of finite/non-finite distinction applies to modals in Mandarin Chinese. Hence, as far as non-root modality for the past is concerned, Mandarin Chinese appears rather distinguished from such languages as English, German, and Italian. A natural question to be raised at this point is how Mandarin Chinese expresses the epistemic and metaphysical readings that are expressed by the "nonroot modal + Perf have" construction in English. This question can be broken down into several sub-questions. To start with, does the same epistemic/metaphysical ambiguity for non-root modals for the past exist in Mandarin Chinese? If so, what construction(s) en$\operatorname{code}(\mathrm{s})$ that ambiguity? Or, how is the construction that expresses the epistemic reading related to, and/or distinguished from, the construction that expresses the metaphysical reading? On a more theoretical level, for the metaphysical reading, what element, if any, assumes the function of the perfect aspectual particle have in English, to back-shift the temporal perspective of the non-root modal to a past time relative to the speaker's utterance time? Do English-type languages and Mandarin Chinese actually appeal to the same underlying compositional principles to express non-root modality for the past? How exactly is the semantics of non-root modality for the past derived in Mandarin Chinese?

The remainder of this paper is devoted to addressing these questions above. In the next section, I will show how the epistemic and metaphysical readings of the "non-root modal + Perf have" construction in English are expressed in Mandarin Chinese. Just as in English, the same non-root modals for the past can be used for both readings in Mandarin Chinese. However, the metaphysical reading, but not the epistemic reading, requires the presence of an aspectual adverb like reng and hai, both roughly meaning 'still'. Moreover, similarly to the "non-root modal + Perf have" construction in English, the metaphysical reading in Mandarin Chinese also carries a strong counterfactual implicature. In Section 3, I will provide a formal analysis of how the epistemic and metaphysical readings of non-root modals for the past in Mandarin Chinese are derived. In particular, when analyzing the latter reading, I propose that reng and hai are back-shifting operators that evaluate the temporal perspective of non-root modals to a past time. As far as temporal shifting is concerned, the operators behave similarly to the perfect aspectual particle in languages like English, German, and Italian. In Section 4, I discuss some implications of my analysis, and then conclude this paper.

\section{Epistemic and metaphysical readings of non-root modals in Mandarin Chinese}

\subsection{Default temporal perspectives of non-root modals in Mandarin Chinese}

This paper focuses on the epistemic and metaphysical readings of the existential nonroot modal keneng. The discussion can be, mutatis mutandis, extended to other nonroot modal elements such as 或许 huoxu 'maybe' and 应该 yinggai 'should'. The first task that I take up in this section is to demonstrate that the temporal perspective of epistemic keneng is the speaker's utterance time. My arguments are two-fold. First, I show that with regard to the temporal perspective, epistemic keneng patterns with English epistemic might, rather than with possible. Unembedded epistemic might necessarily has a temporal perspective anaphoric to the speaker's utterance time. Second, I provide alternative explanations of those examples that Chen (2012b) employed to support her claim that without any "extra lexical or morpho-syntactic resources," epistemic keneng can have past and future temporal perspectives. 
Let me begin with Mondadori's (1978) observation regarding English might that the two sentence schemas in 8 are both ambiguous between epistemic and metaphysical readings, and that the relative position of yesterday to might does not affect the ambiguity. The sentences in 9 are actual examples illustrating the schemas. The epistemic reading of $9 \mathrm{a}-\mathrm{b}$ states that they forming a band yesterday is possible based on the speaker's epistemic state at her utterance time. This possibility is not evaluated on the basis of the speaker's belief state during (any sub-interval of) yesterday. The claim is consistent with the idea pursued by Abusch (1997) and Stowell (2004), who showed that unembedded epistemic might comes with a temporal perspective that is anaphoric to the speaker's utterance time. According to these authors, epistemic might cannot have a temporally "dislocated" perspective. Even when it is used to talk about a past event, epistemic might is not evaluated against a past time ${ }^{\mathrm{b}}$. For the epistemic reading of $9 \mathrm{a}-\mathrm{b}$, the temporal phrase yesterday does not modify might; rather, it modifies the verb phrase formed a band. According to Condoravdi's (2002) analysis and as already indicated in 2a above, the temporal perspective for might is valued by the topmost PRES. The metaphysical reading of $9 \mathrm{a}-\mathrm{b}$, by contrast, states that the possibility for them to form a band existed (in a sub-interval of) yesterday. In this reading, the temporal perspective for might is back-shifted to (a sub-interval of) yesterday, and as discussed above, the temporal back-shifting is achieved by have scoping over might in LF.

(8) a. $\alpha$ might have $\phi$-ed yesterday.

b. $\alpha$ yesterday might have $\phi$-ed ${ }^{c}$.

(9) a. They might have formed a band yesterday.

b. ?They yesterday might have formed a band.

The two sentence schemas in 10, by contrast, contain the adjectival modal element possible. The sentences in 11 are actual examples illustrating the schemas. According to Mondadori (1978), 11a is not semantically equivalent to 11b. For the former sentence, yesterday directly modifies possible. The possibility for them to form a band is evaluated against (a sub-interval of) yesterday - a time different from the speaker's utterance time even without any temporal shifting operator comparable to have in 1 and 9. Thus, the interpretation of 11a roughly corresponds to the metaphysical reading of the sentences in 9 . Moreover, 11a carries an implicature that they did not form a band, nor does the possibility for them to form a band exist anymore as of the speaker's utterance time. For 11b, yesterday modifies the verb phrase formed a band, and serves to give the topic time for the associated event. The temporal perspective for possible is the speaker's utterance time, and the interpretation of $11 \mathrm{~b}$ roughly corresponds to the epistemic reading of the sentences in 9 .

(10) a. It was possible yesterday for $\alpha$ to $\phi$.

b. It is possible for $\alpha$ to have $\phi$-ed yesterday.

(11) a. It was possible yesterday for them to form a band.

b. It is possible for them to have formed a band yesterday.

I claim that when not embedded under an attitude verb or any other temporal operator, epistemic keneng in Mandarin Chinese patterns with might, but not with possible, 
in that its temporal perspective is always the speaker's utterance time. The claim is evident from the observation that the temporal phrase 上星期三 shang xingqisan 'last Wednesday' in all the sentences in $12^{\mathrm{d}}$, no matter where it appears ${ }^{\mathrm{e}}$, only can be understood to specify the topic time for the (possible) event of the team working overtime. Under no circumstance can the phrase refer to the time frame of the speaker's epistemic state. Rather, all the sentences in 12 describe the speaker's epistemic state at her utterance time. Hence, the behavior of shang xingqisan in 12 is very similar to yesterday in the sentences of 9 under the epistemic reading. A difference, though, is that shang xingqisan cannot serve as a reference time against which the metaphysical possibility of the team working overtime is evaluated, a point on which I will elaborate shortly ${ }^{f}$.

(12) a. 他们组上星期三可能加了班。 tamen_zu_shang_xignqisan_keneng_jia_le_ban. them_team_last_Wednesday_may/might_add_LE__shift It is possible that their team worked overtime last Wednesday.

b. 他们组可能上星期三加了班。 tamen_zu_keneng_shang_xignqisan_jia_le_ban. them_team_may/might_last_Wednesday_add_LE_shift It is possible that their team worked overtime last Wednesday.

c. 上星期三他们组可能加了班。 shang_xingqisan_tamen_zu_keneng_jia_le_ban. last_Wednesday_them_team_may/might_add_LE__shift. It is possible that their team worked overtime last Wednesday.

Chen (2012b), however, claimed that epistemic keneng in Mandarin Chinese is allowed to have present, past, and future temporal perspectives. According to my Mandarin Chinese consultants, the examples that Chen (2012b) cited to argue for past temporal perspectives for epistemic keneng are at best marginal, as far as the readings she intended for the examples are concerned. Furthermore, to the extent that her example sentences are acceptable, they are better understood as being embedded under a covert past attitude verb. For instance, one of her examples (ex. 21, with some stylistic adjustments) is the following:

Context: You and your friend agreed to meet at 41 St.'s 7-11, but you didn't see him at the appointed time. The 7-11 clerk told you there's another 7-11 on 41 St. so you hastened to go there but still didn't find him. When you came home, you got his call. He says, 'Why didn't you wait for me? I was only 15 minutes late!' You reply:

(13) 你可能去了另外一家7-11。

ni_keneng_qu_le_lingwai_yi_jia_7-11.

you_may/might_go_LE_another_one_CL_7-11

You might have gone to another 7-11.

Chen (2012b) claimed that epistemic keneng in 13 can be understood as having a past temporal perspective. I agree with her on this particular point. However, she further claimed that the past temporal perspective is achieved without "any particular grammatical element" as a temporal shifter. In making the second claim, however, Chen did not consider the possibility of COVERT shifters. In fact, in order for epistemic keneng 
in 13 to have a past temporal perspective, the sentence needs to be understood as being embedded under a covert past attitude verb, similar to the overt counterpart in 14 . Then, the past temporal perspective of keneng is not truly past, but anaphoric to the past belief time that comes with the embedding attitude verb. That is, the temporal perspective of keneng is still present relative to the past belief time ${ }^{g}$.

(14) (我当时以为) 你可能去了另外一家7-11。 (wo_dangshi_yiwei)_ni_keneng_qu_le_lingwai_yi_jia_7-11. I__at that time_think__you_may/might_go__LE_another_one_CL_7-11 At that time I thought that you might have gone to another 7-11.

Chen (2012b) also posited that epistemic keneng can have a future temporal perspective. Her example sentence (ex. 23, with some stylistic adjustments), along with the accompanying context, is repeated below:

Context: Japanese construction company Obayashi wants to build an elevator to space and transport passengers to a station about a tenth the distance to the moon. The elevator would use super-strong carbon nanotubes in its cables and could be ready as early as 2050, according to Tokyo-based Obayashi.

（15）2050年将可能搭电梯上外太空。

2050_nian__iang_keneng_da_dianti_shang_waitaikong. 2050_year_FUT__may/might_take_elevator_go up_outer space

(Human being) will be likely to go up to the outer space by an elevator by 2050.

I do not think that epistemic keneng in 15 has a true future temporal perspective under the given context. Rather, keneng is evaluated against what the speaker knows (about Obayashi's plan and possibly other things) at her utterance time, not against the speaker's knowledge in 2050. After all, the sentence could be felicitously uttered by a speaker who died in 2012 shortly after uttering the sentence and who would have no epistemic state whatsoever in $2050^{\mathrm{h}}$.

Hence, the epistemic reading of unembedded keneng always has a temporal perspective that is anaphoric to the speaker's utterance time. Even when the speaker makes a judgment about the past or the future, she still bases her judgment on her epistemic state at the utterance time. A natural question to ask at this point is: How about the temporal perspective of the metaphysical reading of unembedded keneng? I claim that metaphysical keneng also has a present temporal perspective by default, which, as will be discussed in the next subsection, can be back-shifted by certain temporal operators. The claim about a default present temporal perspective for metaphysical keneng has already been indicated by the observation that shang xignqisan in 12 cannot be the time to which metaphysical keneng is relativized. For if it could, in theory one would be able to add another temporal phrase denoting a time later than last Wednesday to serve as the topic time of the (possible) event of the team working overtime. Doing so guarantees the resulting sentences (if grammatical) to have a metaphysical reading, viz., a reading about the possible evolution of the world with respect to the team working overtime after last Wednesday. The prediction, however, is not borne out: adding 上星期五 shang xingqiwu 'last Friday' to the sentences in 12 to modify 加(了)班 jia (le) ban 'worked overtime' would lead to ungrammatical sentences as in $16^{\mathrm{i}}$. The 
ungrammaticality can be blamed on nothing else but inherent temporal requirements in the metaphysical use of keneng.

（16） a. *他们组上星期三可能上星期五加 (了)班。 tamen_zu_shang_xingqisan_keneng_shang_xingqiwu_jia_(le)_ban. them_team_last_Wednesday_may/might_last_Friday_add_LE_shift Intended: It was possible last Wed. that their team would work overtime last Fri.

b. *上星期三他们组可能上星期五加 (了)班。 shang_xingqisan_tamen_zu_keneng_shang_xingqiwu_jia_(le)_ban. last_Wednesday_them_team_may/might_last_Friday_add_LE_shift

\subsection{Reng and hai as temporal shifters for metaphysical modals}

From the previous subsection, we can conclude that the temporal perspective of unembedded keneng, whether in the epistemic or metaphysical reading, is by default anchored to the speaker's utterance time. An important implication of this temporal restriction on keneng is that the metaphysical reading expressed by the English "nonroot modal + Perf have" construction, with a PAST temporal perspective, cannot be expressed by means of keneng, unless there is a mechanism that can back-shift the temporal perspective of the modal. Does such a mechanism exist in Mandarin Chinese?

The answer is positive. To see this, let me start with mentioning Xie's (2012) observation that such aspectual adverbs as reng and hai, both roughly translated as 'still', can salvage the temporal clash between the abilitative modal participle 得 $d e$ 'can, able to' in Mandarin Chinese and a past-denoting temporal phrase. Generally speaking, the abilitative use of $d e$ is not compatible with a past-denoting temporal phrase serving as the topic time for the modal. The incompatibility, however, disappears when the temporal phrase is associated with such aspectual adverbs as reng and hai. This claim is illustrated by the sentence in 17 (Xie's 2012: ex. 56, with some stylistic adjustments).

(17) 张三昨天* (还) 做得完那些作业

zhangsan_zuotian_"(hai)_zuo_de_wan__neixie_zuoye.

Zhangsan_yesterday_still_do_ability modal_finished_those_homework

Zhangsan was still able to finish those homework assignments yesterday.

According to Xie's (2012) proposal, the fact that the abilitative modal de cannot occur with a past-denoting temporal phrase is due to the (idiosyncratic) requirement that the topic time of the abilitative use of $d e$ "should coincide with or follow the evaluation time [i.e., temporal perspective - author] of $d e$, which is the utterance time by default" (p. 387). This requirement looks very similar to what I have said regarding the default temporal perspective of the modal keneng. Furthermore, according to Xie (2012), when an abilitative de sentence contains a past-denoting temporal phrase, aspectual adverbs like reng and hai can shift the temporal perspective of $d e$ from the default, speaker's utterance time to (a sub-interval of) the topic time.

I observe that such aspectual adverbs as reng and hai also can back-shift the temporal perspective of keneng from the speaker's utterance time to a past timej. The backshifting leads to a metaphysical interpretation of keneng. The sentence in 18a only has an epistemic reading in which the speaker believes that the event of Zhangsan winning the game occurred yesterday morning. This reading corresponds to the epistemic 
reading of the English example sentence in 1. However, adding reng or hai to 18a would give rise to a metaphysical reading, which is missing from the original sentence. The sentence in 18b has a reading that describes the metaphysical possibility, valid during (a subinterval of) yesterday morning, for Zhangsan to win the game at some time later than yesterday morning. The past temporal phrase 昨天上午 zuotian shangwu 'yesterday morning' in the sentence provides a time frame against which keneng is evaluated, rather than being the topic time of the winning-the-game event. The sentence remains grammatical (though admittedly less natural) if another temporal phrase denoting some time future to yesterday morning (e.g., (zuotian) xiawu '(yesterday) afternoon') is added before 赢了那场比赛 ying le nei chang bisai 'won the game' as a topic time of the (potential) winning-the-game event. This is illustrated in 19. In addition, the metaphysical reading of $18 \mathrm{~b}$ comes with a strong counterfactual implicature that the possibility for Zhangsan to win the game did not materialize, and is no longer valid, at the speaker's utterance time. Therefore, the metaphysical reading of $18 \mathrm{~b}$ is very similar to that of the English sentence in $1 \mathrm{~b}$. The sentence pairs in 20-21 illustrate the same pattern: the a sentences have an epistemic reading, and adding reng or hai to the a sentences forces out, so to speak, a metaphysical reading.

(18) a. 张三昨天上午可能赢了那场比赛。 zhangsan_zuotian_shangwu_keneng_ying_le_nei_chang_bisai. Zhangsan_yesterday__morning_may/might_win_LE_that_CL_game It is possible that Zhangsan won the game yesterday morning.

b. 张三昨天上午仍/还可能赢了那场比赛。

zhangsan_zuotian_shangwu_reng/hai_keneng_ying_le_nei_chang_bisai. Zhangsan_yesterday_morning_still_may/might_win_LE_that_CL_game It was still possible yesterday morning for Zhangsan to have won the game.

（19）？张三昨天上午仍/还可能下午赢了那场比赛。 zhangsan_zuotian_shangwu_reng/hai_keneng_xiawu_ying_le_nei_chang_bisai. Zhangsan_yesterday_morning_still_may/might_afternoon_win_LE_that_CL_game It was still possible yesterday morning for Zhangsan to have won the game yesterday afternoon.

(20) a. 主任昨天可能写了那份报告 zhuren_zuotian_keneng_xie_le_nei_fen_baogao. director_yesterday_may/might_write_LE_that_CL_report It is possible that the director wrote the report yesterday.

b. 主任昨天仍/还可能写了那份报告。 zhuren_zuotian_reng/hai_keneng_xie_le_nei_fen_baogao. director_yesterday_still_may/might_write_LE_that_CL_report It was still possible yesterday for the director to have written the report.

(21) a. 那些股民当时可能卖了手中的股票。 neixie_gumin_dangshi_keneng_mai_le_shou_zhong_de_gupiao. those_stock buyer_at that time_may/might_sell_LE_hand_in_DE_stock It is possible that the stock buyers sold their stocks at that time.

b. 那些股民当时仍/还可能卖了手中的股票。

neixie_gumin_dangshi_reng/hai_keneng_mai_le_shou_zhong_de_gupiao. those_stock buyer_at that time_still_may/might_sell_LE_hand_in_DE_stock It was still possible at that time for the stock buyers to have sold their stocks. 
It may be a difficult task to separate metaphysical modality from epistemic modality (Condoravdi 2002, Abusch 2012). Thus, it is worth emphasizing here that adding reng and hai transforms the a sentences in 18, 20, and 21 from an epistemic reading to a metaphysical reading, rather than merely changing the temporal perspective from the speaker's utterance time to a past time. More specifically, the sentence in $18 \mathrm{~b}$, for example, does not talk about the speaker's epistemic state during yesterday morning, viz., the speaker's belief during yesterday morning that Zhangsan would win the game at some later time. Rather, the sentence describes a POSSIBLE DEVELOPMENT as of yesterday morning with regard to the prospect of Zhangsan winning the game (or not). This claim is evident from the fact that $18 \mathrm{~b}$ does not require the speaker to have any knowledge during yesterday morning regarding Zhangsan winning the game, or anything related to the game at all. The speaker could felicitously utter $18 \mathrm{~b}$ even if she just learned a few seconds prior to uttering the sentence that yesterday morning Zhangsan was fully prepared and in a good position to compete in the game. But Zhangsan broke a leg shortly after starting the game, which the speaker thought was responsible for Zhangsan's eventual loss in the game.

The discussion so far primarily focused on the temporal perspective of the epistemic and metaphysical uses of keneng. Though unembedded keneng in both uses have a present temporal perspective by default, the metaphysical use, but not the epistemic use, allows operators such as reng and hai to shift the temporal perspective from the speaker's utterance time to a past time. In addition, the two uses of keneng also show interesting distinctions with regard to the temporal orientation, viz., the temporal parameter constraining the temporal reference of the prejacent of a modal. The metaphysical use of keneng (as well as other metaphysical modals) is associated with a future temporal orientation, and cannot have past or present temporal orientation (Chen 2012a, b). The intuition behind this constraint is that metaphysical keneng has to do with how things WILL/WOULD develop from the time when the modal is evaluated. By contrast, the epistemic use of keneng allows all three possible temporal orientations: past, present, and future. The reader can refer to Chen (2012a, b) for extensive discussion on the temporal orientation of epistemic modals in Mandarin Chinese. Thus, between epistemic and metaphysical keneng, only the metaphysical use allows a past temporal perspective, which, in turn, combines with a future temporal orientation. When keneng has a present temporal perspective and a future temporal orientation, it may be ambiguous between epistemic and metaphysical readings. In theory, the two readings can be distinguished by checking whether a particular reading is about the speaker's subjective knowledge or is about how the relevant proposition will/would come about independently of speaker perception and judgment. But in practice, telling the two readings apart can be a very tricky task. It is beyond the scope of the current paper to provide extensive discussion on this topic. The interested reader can refer to such works as Condoravdi (2002), Abusch (2012), and Klecha (2012) for relevant discussion.

\subsection{Constraints on reng and hai as temporal shifters}

The previous subsection showed that aspectual adverbs like reng and hai can serve as temporal shifting operators in non-root modal contexts. At the same time, I would like 
to point out that temporal shifting by such aspectual adverbs is constrained, and not freely available to all sentences that contain a non-root modal. First, reng and hai can only serve as back-shifters, and can never forward-shift the temporal perspective of a non-root modal. This fact is evident from the following observation. The sentence in 22 cannot have the metaphysical reading that it will be metaphysically possible during (a sub-interval of) tomorrow for Zhangsan to leave the team at some time future to tomorrow. Otherwise, one would be able to specify a reference time for the (potential) leaving event and have an acceptable sentence 23 (cf., 19). Rather, the sentence in 22 only has an epistemic reading, which describes the speaker's belief state at her utterance time with regard to the (potential) event of Zhangsan leaving the team the next day. In this reading, mingtian is the topic time of the event, not a time against which the metaphysical possibility of Zhangsan leaving the team is evaluated.

（22）张三明天仍可能离开那支球队。 zhangsan_mingtian__reng_keneng_likai_nei_zhi_qiudui. Zhangsan_tomorrow_still_may/might_leave_that_CL_soccer team It is still possible that Zhangsan will leave the soccer team tomorrow.

(23) */??张三明天仍可能后天离开那支球队。 zhangsan_mingtian_reng_keneng_houtian_likai_nei_zhi_qiudui. Zhangsan_tomorrow_still_may/might_day after tomorrow_leave_that_CL_soccer team Intended: It will still be possible tomorrow for Zhangsan to leave the soccer team the day after.

Second, for sentences that contain only one past-denoting temporal phrase, whether the temporal phrase is intended to modify keneng or the prejacent of the modal affects how readily (or probably even whether) the metaphysical reading is available. The attentive reader might have noticed that in all the b sentences in 18,20 , and 21 , the temporal phrases appear immediately before reng/hai and are intended to modify keneng. When the temporal phrases are moved after keneng, however, it becomes difficult to obtain a metaphysical reading for the resulting sentences, unless a new temporal phrase is added before reng/hai, or such a temporal phrase can be constructed from the pragmatic context. Moreover, this new phrase should denote a time to the past of the time denoted by the original phrase. The sentence in 24, for example, does not have a metaphysical reading. Forcing a reading with a past temporal perspective and a future temporal orientation out of 24 generally requires a temporal phrase to appear overtly, or to be contextually constructed, before reng. Moreover, the temporal phrase needs to denote a time earlier than the speaker's yesterday morning (say, 前天晚上 qiantian wanshang 'the night before last') ${ }^{1}$.

(24) */??张三仍可能昨天上午赢了那场比赛。 zhangsan_reng_keneng_zuotian_shangwu_ying_le_nei_chang_bisai. Zhangsan_still_may/might_yesterday_morning_win_LE_that_CL_game Intended: It was possible (earlier) for Zhangsan to have won the game yesterday morning.

To summarize, non-root modals in Mandarin Chinese, represented by keneng in this paper, by default have a temporal perspective anaphoric to the speaker's utterance time. This generalization holds true of both the epistemic and metaphysical readings. The 
two uses, however, show interesting differences with regard to temporal orientation. Keneng can be used as a metaphysical modal for the past, with a past temporal perspective and a future temporal orientation. For such a use, keneng needs to be modified by such aspectual adverbs as reng and hai, which, in turn, typically associate with a temporal phrase denoting a past time. Reng and hai can back-shift the temporal perspective of keneng from the default, speaker's utterance time toward the past.

\section{Representing temporal shifting in Mandarin Chinese}

In this section, I will provide a formal semantic analysis of how the metaphysical reading of non-root modals for the past is derived in Mandarin Chinese. The analytic intuition I would like to pursue is rather simple. Basically, along the same lines as Xie's (2011, 2012) treatment of temporal shifting elements in the context of English nonroot modals for the past and Mandarin Chinese abilitative modal de, I posit that aspectual adverbs like reng and hai can serve the same function assumed by the perfect aspectual particle have in English as a temporal back-shifting operator. Such aspectual adverbs can shift the temporal perspective of a non-root modal to a past time, which is generally (a sub-interval of) the time denoted by the temporal phrase that modifies the non-root modal. After the temporal perspective of the non-root modal is back-shifted, it cannot receive an epistemic reading any more, because the epistemic reading necessarily requires a temporal perspective anaphoric to the speaker's utterance time. Rather, the non-root modal with a past temporal perspective receives a metaphysical reading.

The remaining task, then, comes down to spelling out this analytic intuition about the metaphysical reading of non-root modals for the past in Mandarin Chinese. The basic formal mechanism that I will use is from Xie (2011, 2012). Before approaching the metaphysical use of keneng and temporal shifting by reng and hai, I would like to first show how to derive the (epistemic) reading of 25, repeated from 18a. To begin with, the verb final $l e$ in Mandarin Chinese expresses perfectivity and has a (relative) past interpretation (Smith 1997, Klein et al. 2000, Lin 2006). The main analysis I develop in this paper does not depend on what the semantic definition of le is actually like. In this paper, I basically adopt Lin's (2006) definition of the perfective marker $l e^{\mathrm{m}}$ :

(25) 张三昨天上午可能赢了那场比赛。 zhangsan_zuotian_shangwu_keneng_ying_le_nei_chang_bisai. Zhangsan_yesterday_morning_may/might_win_LE_that_CL_game It is possible that Zhangsan won the game yesterday morning.

$$
[[l e]]=\lambda \mathrm{P} \lambda \mathrm{t}_{\text {etop }} \lambda \mathrm{w} . \exists \mathrm{t} \exists \mathrm{e}\left[\mathrm{t} \subseteq \mathrm{t}_{\text {etop }} \& \mathrm{P}(\mathrm{e})(\mathrm{w})(\mathrm{t})\right] \quad \text { where } \mathrm{t}_{\text {etop }}<\mathrm{t}_{0}{ }^{\mathrm{n}}
$$

In prose, the semantics of $l e$, as in 26 , requires the property of an event to hold in $w$ at a sub-interval of the topic time of the event. I use $t_{\text {etop }}$ to stand for the topic time of the event. It should be distinguished from $t_{m t o p}$, which stands for the topic time for (the evaluation of) modals. The time $t_{\text {etop }}$ should precede the reference time $t_{0}$ of the event, which, normally speaking, is the speaker's utterance time $t_{\text {now }}{ }^{\circ}$. Essentially, the semantic definition of $l e$ in 26 allows it to function as a past tense operator.

The semantics of the modal keneng can be defined along the lines of 27, by adopting Kratzer's $(1981,1991)$ framework of modality. In the definition, $M B$ stands for the modal 
base of keneng, which can be either epistemic or metaphysical. According to the semantic definition, keneng requires that the relevant proposition hold true in some world $w^{\prime}$ accessible from the evaluation world $w$ at the temporal perspective $t$ (Xie 2011).

$$
[[\text { keneng }]]=\lambda \mathrm{P} \lambda \mathrm{w} \lambda \mathrm{t} . \exists \mathrm{w}^{\prime}\left[\mathrm{w}^{\prime} \in \mathrm{MB}(\mathrm{w}, \mathrm{t}) \& \mathrm{P}\left(\mathrm{w}^{\prime}\right)\right]
$$

The sentence in 25 only has an epistemic reading. The temporal phrase 昨天上午 zuotian shangwu 'yesterday morning' is the topic time of the (possible) event of Zhangsan winning the game (i.e., $t_{\text {etop }}$ ). It is generally accepted that non-root modals involve a raising construction (as compared to a control construction) and take a proposition as the complement (Hacquard 2006, Tsai 2001, among others). For the sake of convenience, I assume the LF in 28 for the sentence in $25^{\mathrm{p}}$. The step-by-step semantic derivation of the sentence is given in 29. In the last step, I assume PRES to be the base world $w_{0}$ and the speaker's utterance time. Recall that the metaphysical modal base of non-root modals for the past has to do with possible future development of an event relative to a past temporal perspective (i.e., a past temporal perspective combined with a future temporal orientation). The semantics in $29 \mathrm{e}$ can only give rise to an epistemic reading, for it is about a possible past event seen from the perspective of the speaker's utterance time (i.e., a present temporal perspective with a past temporal orientation). I think that the semantics correctly describes the meaning of the sentence: that Zhangsan winning the game some time yesterday morning is a true proposition in some belief world of the speaker.

(28) ${ }_{s 5}$ PRES [s4 keneng [s3 [s2 le [s1 Zhangsan ying nei chang bisai ] ] [zuotian shangwu]]]]

(29) a. [[ S1]] $=\lambda e \lambda w \lambda t$. [[ Z win the game ]] $(e)(w)(t)$

b. $[[\mathrm{S} 2]]=\lambda \mathrm{t}_{\text {etop }} \lambda \mathrm{w} . \exists \mathrm{t} \exists \mathrm{e}\left[\mathrm{t} \subseteq \mathrm{t}_{\text {etop }} \&[[\mathrm{Z}\right.$ win the game $\left.]](\mathrm{e})(\mathrm{w})(\mathrm{t})\right]$

c. $[[\mathrm{S} 3]]=\lambda \mathrm{w} . \exists \mathrm{t} \exists \mathrm{e}[\mathrm{t} \subseteq[-1$, morning $] \&[[\mathrm{Z}$ win the game $]](\mathrm{e})(\mathrm{w})(\mathrm{t})]$

d. $[[\mathrm{S} 4]]=\lambda \mathrm{w} \lambda \mathrm{t} . \exists \mathrm{w}^{\prime}\left[\mathrm{w}^{\prime} \in \mathrm{MB}(\mathrm{w}, \mathrm{t}) \& \exists \mathrm{t}_{1} \exists \mathrm{e}\left[\mathrm{t}_{1} \subseteq[-1\right.\right.$, morning $] \&\left[[\mathrm{Z}\right.$ w.t.g.] $\left.](\mathrm{e})\left(\mathrm{w}^{\prime}\right)\left(\mathrm{t}_{1}\right)\right]$

e. $[[\mathrm{S} 5]]=\exists \mathrm{w}^{\prime}\left[\mathrm{w}^{\prime} \in \mathrm{MB}\left(\mathrm{w}_{0}, \mathrm{t}_{\text {now }}\right) \& \exists \mathrm{t}_{1} \exists \mathrm{e}\left[\mathrm{t}_{1} \subseteq[-1\right.\right.$, morning $] \&[[\mathrm{Z}$ w.t.g. $\left.]](\mathrm{e})\left(\mathrm{w}^{\prime}\right)\left(\mathrm{t}_{1}\right)\right]$

Now, let us consider the sentence in 30 (repeated from 18b). On the surface, the sentence is minimally different from 25 in containing reng 'still' between 昨天上午 zuotian shangwu 'yesterday morning' and keneng 'may/might'. When reng is used as an aspectual adverb, the sentence has a metaphysical reading with a past temporal perspective and a future temporal orientation. It is reng that back-shifts the temporal perspective of keneng from the default, speaker's utterance time to a past time.

(30) 张三昨天上午仍可能赢了那场比赛。

zhangsan_zuotian_shangwu_reng_keneng_ying_le_nei_chang_bisai.

Zhangsan_yesterday_morning_still_may/might_win_LE_that_CL_game

It was still possible yesterday morning for Zhangsan to have won the game.

I would like to point out that the sentence in 30 , in its metaphysical reading, does not have the same LF as 25. First, the temporal phrase 昨天上午 zuotian shangwu 'yesterday morning' serves as the topic time for evaluating the modal keneng, not for referencing the (possible) event of Zhangsan winning the game. Second, I assume that reng directly modifies keneng, not the modal proposition ${ }^{\mathrm{q}}$. The LF that I assume for 30 is given below in (31):

(31) [s4 zuotian shangwu [s3 [reng keneng] [s2 le [s1 Zhangsan ying nei chang bisai ]]]] 
The aspectual adverb reng is a temporal back-shifter, which re-evaluates the temporal perspective $\left(t_{\text {eval }}\right)$ of keneng to a sub-interval of the topic time of the modal $\left(t_{\text {mtop }}\right)$. Its semantics can be defined in 32 . The " $t_{\text {mtop }} \leq t_{\text {now" }}$ " presupposition in the definition is responsible for the unacceptability of such sentences as in 33, which involves a future time intended as the topic time of metaphysical keneng. After applying the backshifting operator to keneng, the temporal perspective of the modal is "overridden" from the speaker's utterance time to a sub-interval of $t_{m t o p}$, as shown in 34 .

(33) 张三明天仍可能 (后天) 赢了那场比赛。

"zhangsan_mingtian__reng_keneng_(houtian)_ying_le_nei_chang_bisai.

Zhangsan_tomorrow_still_may/might_(the-day-after-tomorrow)_win_LE_that_CL_game Intended: It will still be possible tomorrow for Zhangsan to win the game (the day after).

(34) $[[$ reng keneng $]]=\lambda \mathrm{P} \lambda \mathrm{t}_{\mathrm{mtop}} \lambda \mathrm{w} . \exists \mathrm{t}_{\text {eval }}\left[\mathrm{t}_{\text {eval }} \subseteq \mathrm{t}_{\mathrm{mtop}} \& \exists \mathrm{w}^{\prime}\left[\mathrm{w}^{\prime} \in \mathrm{MB}\left(\mathrm{w}, \mathrm{t}_{\text {eval }}\right) \& \mathrm{P}\left(\mathrm{w}^{\prime}\right)\right]\right]$, where $t_{\text {mtop }} \leq t_{\text {now }}$

It is obvious from 34 that in the special case where $t_{m t o p}=t_{\text {now }}$, reng merely has a vacuous effect on shifting the temporal perspective of metaphysical keneng, because $t_{\text {eval }}$ remains to be the default $t_{\text {now }}$ after the application of reng to keneng. For example, when intended for a metaphysical reading, the sentence in 35, which contains the temporal perspective back-shifter reng, describes how things may develop from the speaker's utterance time, with regard to Zhangsan's (possible) trip to Beijing. Hence, in the metaphysical reading, keneng has a present temporal perspective and a future temporal orientation. At the same time, the sentence in 35 has an epistemic reading, which describes a subjective judgment by the speaker about Zhangsan's (possible) trip to Beijing, based on the speaker's knowledge at her utterance time. Clearly, in the epistemic reading, keneng has a present temporal perspective and a future temporal orientation, as well. As I indicated in section 2.2, how to distinguish the two readings with reliable empirical tests is an interesting yet very difficult topic, which I do not address in this paper.

（35）张三仍可能明天这个时候到北京。

zhangsan_reng_keneng_mingtian_zhe_ge_shihou_dào_beijing.

Zhangsan_still_may/might_tomorrow_this_CL_time_arrive_Beijing.

It is possible that Zhangsan will arrive in Beijing this time tomorrow.

Now let us turn to the step-by-step semantic derivation of the sentence in 30, which is given in 36. Because the modal keneng is evaluated against some time in the past (i.e., (a sub-interval of) the speaker's yesterday evening), not against the speaker's utterance time, it has a past temporal perspective. Then, the modal base cannot be an epistemic one, but has to be a metaphysical one. Furthermore, recall that the metaphysical reading of non-root modals for the past has to do with the future development of an event relative to the temporal perspective. Hence, the event time of Zhangsan winning the game should be after the temporal perspective of keneng. The end result of the derivations, given in 36d, stipulates that Zhangsan winning the game in a time future to yesterday morning is an evolution possibility consistent with how things would develop at the relevant evaluation interval during yesterday morning. I think that 
the semantics accurately describes Mandarin Chinese native speakers' intuition about what the sentence in 30 means.

(36) a. $[[\mathrm{S} 1]]=\lambda \mathrm{e} \lambda \mathrm{w} \lambda \mathrm{t}$. [[ $\mathrm{Z}$ win the game $]](\mathrm{e})(\mathrm{w})(\mathrm{t})$

b. $[[\mathrm{S} 2]]=\lambda \mathrm{t}_{\text {etop }} \lambda \mathrm{w} . \exists \mathrm{t} \exists \mathrm{e}\left[\mathrm{t} \subseteq \mathrm{t}_{\text {etop }} \&[[\mathrm{Z}\right.$ win the game $\left.]](\mathrm{e})(\mathrm{w})(\mathrm{t})\right]$

c. $[[\mathrm{S} 3]]=\lambda \mathrm{t}_{\text {mtop }} \lambda w \lambda \mathrm{t}_{\text {etop }} . \exists \mathrm{t}_{\text {eval }}\left[\mathrm{t}_{\text {eval }} \subseteq \mathrm{t}_{\text {mtop }} \& \exists \mathrm{w}^{\prime}\left[\mathrm{w}^{\prime} \in \mathrm{MB}\left(\mathrm{w}, \mathrm{t}_{\text {eval }}\right) \& \exists \mathrm{t} \exists \mathrm{e}\right.\right.$ $\left[t \subseteq t_{\text {etop }} \&\left[\left[\mathrm{Z}\right.\right.\right.$ win the game]] $\left.\left.\left.(\mathrm{e})\left(\mathrm{w}^{\prime}\right)(\mathrm{t})\right]\right]\right]$, where $\mathrm{t}_{\text {mtop }} \leq \mathrm{t}_{\text {now }}$ and where $\mathrm{t}_{\text {etop }}<\mathrm{t}_{\text {now }}$ d. $[[\mathrm{S} 4]]=\lambda \mathrm{w} \mathrm{t}_{\text {etop }} . \exists \mathrm{t}_{\text {eval }}\left[\mathrm{t}_{\text {eval }} \subseteq[-1\right.$, morning $] \& \exists \mathrm{w}^{\prime}\left[\mathrm{w}^{\prime} \in \mathrm{MB}\left(\mathrm{w}, \mathrm{t}_{\text {eval }}\right) \& \exists \mathrm{t} \exists \mathrm{e}\left[\mathrm{t} \subseteq \mathrm{t}_{\text {etop }}\right.\right.$ $\&[[\mathrm{Z}$ win the game $\left.\left.\left.]](e)\left(w^{\prime}\right)(t)\right]\right]\right]$, where $[-1$, morning $] \leq t_{\text {now }}$ and where $t_{\text {etop }}<t_{\text {now }}$

In its metaphysical reading, the sentence in 30 has a strong counterfactual implicature that Zhangsan did not actually win the game in the end, and that at the speaker's utterance time, it is no longer possible for Zhangsan to win the game. My explanation of the counterfactual implicature with the metaphysical reading of sentences like 30 goes along the same lines as Condoravdi's (2002) idea. Aspectual adverbs such as reng and hai shift the temporal perspective of metaphysical keneng in 30 from the speaker's utterance time to yesterday morning. The temporal back-shifting widens the domain of metaphysical possibilities that keneng quantifies over. This widening of the domain of quantification has to serve some (extra-)linguistic purpose. A very plausible reason is that the metaphysical possibility of Zhangsan winning the game has been ruled out from the domain of quantification for keneng with the speaker's utterance time as the temporal perspective. That is to say, the metaphysical possibility is no longer a valid one at the speaker's utterance time. In addition, the dismissal of the possibility from the domain of quantification for keneng cannot be because the possibility has been actualized at the speaker's utterance time. For if it has been actualized, the cooperative speaker should not use a metaphysical modal sentence to describe the possibility, to begin with. Per the Gricean Maxim of Quantity, the hearer would naturally infer that the speaker intends to communicate that the past metaphysical possibility was not an actualized one ${ }^{\mathrm{r}}$.

In the remainder of this section, I address some restrictions on the availability of metaphysical readings for non-root modals for the past. First, it has been noted in the previous section that aspectual adverbs like reng and hai can only function as a BACKSHIFTING operator, and cannot forward-shift the temporal perspective. I encode this restriction in the requirements " $t_{\text {mtop }} \leq t_{\text {now }}$ " and " $t_{\text {eval }} \subseteq t_{\text {mtop }}$ " in the semantics of such aspectual adverbs.

Second, it has been noted that the metaphysical reading of keneng with a past temporal perspective is most readily available when a past-denoting temporal phrase appears before reng and hence serves as $t_{m t o p}$, regardless whether there is another pastdenoting temporal phrase after keneng to serve as $t_{\text {etop }}$. When a sentence contains a $t_{\text {etop }}$ after keneng but not a $t_{m t o p}$ before reng, however, it cannot have a metaphysical reading, unless a $t_{m t o p}$ can be constructed from the pragmatic context. Without any extra contextual support, the sentence in 24 , reproduced in 37 below, does not have a metaphysical reading.

(37) $* / ?$ ?张三仍可能昨天上午赢了那场比赛。 zhangsan_reng_keneng_zuotian_shangwu_ying_le_nei_chang_bisai. Zhangsan_still_may/might_yesterday_morning_win_LE_that_CL_game Intended: It was possible (earlier) for Zhangsan to have won the game yesterday morning. 
The sentence in 37 has the LF in 38a and the semantic interpretation in 38b (unnecessary detail omitted). Here, I assume that the LF has a PRES operator at the topmost level, which contains base world $w_{0}$ and the speaker's utterance time. The modal keneng is evaluated against the topic time anaphoric to the speaker's utterance time. At the same time, the (potential) event of Zhangsan winning the game fell within yesterday morning. Thus, keneng has a present temporal perspective and a past temporal orientation, which is the temporal pattern for the epistemic reading, not for the metaphysical reading. This is not surprising, because the temporal shifting operator reng, after working on PRES, has a vacuous effect on the temporal perspective of keneng. However, when an appropriate pragmatic context licenses a metaphysical reading of the sentence in 37 , it removes the topmost PRES and replaces it with a time prior to the topic time zuotian shangwu 'yesterday morning', thus leading to a metaphysical reading.

(38) a. [ ${ }_{s 5}$ PRES [ ${ }_{s 4}$ [reng keneng] [s3 [s2 le $\left[_{s 1}\right.$ Zhangsan ying bisai ]] zuotian shangwu]]]] b. $[[\mathrm{S} 5]]=\exists \mathrm{w}^{\prime}\left[\mathrm{w}^{\prime} \in \mathrm{MB}\left(\mathrm{w}_{0}, \mathrm{t}_{\text {now }}\right) \& \exists \mathrm{t} \exists \mathrm{e}[\mathrm{t} \subseteq[-1\right.$, morning $]$ \& [[ $\mathrm{Z}$ win the game $\left.\left.\left.]\right](\mathrm{e})\left(\mathrm{w}^{\prime}\right)(\mathrm{t})\right]\right]$

So far in this section, I provided a formal explanation of the observation that the introduction of an aspectual adverb like reng or hai into a sentence containing a nonroot modal for the past can give rise to a metaphysical interpretation of the modal. The essence of my analysis is that such aspectual adverbs can shift the temporal perspective of the modal toward the past. A remaining, natural question to ask is what makes aspectual adverbs like reng and hai able to back-shift the temporal perspective of nonroot modals for the past. Unfortunately, at this point I do not have a definite answer to this question, and will merely sketch a conjecture in an informal manner. Recall that reng and hai can be used, comparable to English still (Michaelis 1993, Ippolito 2007), to mean that a state/event has/had been going on continuously UP TO a reference time ${ }^{\mathrm{s}}$. For example, reng and hai in 39 modifies 在吃 zai chi 'eating', and the reference time is 现在 xianzai 'now'. The sentence comes with the inference that the person has been eating for at least an hour.

（39）一个小时前我看到他在吃饭, 他现在仍/还在吃饭。

yi_ge_xiaoshi_qian_wo_kandao_ta_zai_chifan, ta_xianzai_reng/hai_zai_chifan. one_CL_hour_ago_I_see_he_PROG_eat, he_now_still_PROG_eat I saw him eating an hour ago, and he is still eating now.

When an aspectual adverb reng or hai appears before, and thus modifies, keneng intended as a non-root modal for the past, it requires that the relevant possibility had continued up to a past reference time. This past reference time is either available from the linguistic context or constructed from the pragmatic context, and serves as the temporal perspective for the modal. As far as non-root modals for the past are concerned, the past temporal perspective is a hallmark of the metaphysical reading. I think this is why reng and hai can "license" a metaphysical reading of non-root modals for the past.

\section{Concluding remarks}

The "non-root modal + Perf(ect) have" construction in English is ambiguous between two readings: an epistemic reading with a present temporal perspective and a past temporal orientation, and a metaphysical reading with a past temporal perspective and a 
future temporal orientation. Condoravdi (2002) explained that the ambiguity arises from the two scope relations allowed between the non-root modal and the perfect aspect. In particular, for the metaphysical reading, the perfect aspectual particle have scopes over the modal and back-shifts the temporal perspective of the modal. Under the assumption that Mandarin Chinese does not have perfect aspect, there is no (near-)counterpart of the "non-root modal + Perf have" construction in Mandarin Chinese. Nevertheless, the Mandarin Chinese constructions that express the two readings of the English construction involve non-root modals for the past, and are closely related in terms of surface form. The primary difference regarding the availability of the two readings is that the metaphysical reading requires the presence of a temporal shifting aspectual adverb.

The epistemic reading of an unembedded non-root modal for the past is evaluated against the speaker's utterance time. Thus, its semantic derivation, which can be realized by assuming the Kratzerian framework of modal semantics, involves no temporal shifting of the temporal perspective. By contrast, when it comes to the metaphysical use of an unembedded non-root modal for the past, such aspectual adverbs as reng and hai can back-shift the temporal perspective of the modal from the speaker's utterance time to some time within the past-denoting topic time of the modal. This topic time either is present in the linguistic context, or can be constructed from the pragmatic context. With a past temporal perspective, the non-root modal can only have a metaphysical reading.

I think that the above discussion of non-root modals for the past in Mandarin Chinese has important theoretical implications. Linguists generally look to three areas for language universality and variation in the realm of natural language meaning: (i) lexical morphemes, (ii) functional morphemes and associated compositional principles, and (iii) pragmatics (von Fintel and Matthewson 2008). Before concluding the paper, I would like to point out that with respect to non-root modals for the past, the difference between Mandarin Chinese and such languages as English, German, and Italian is probably better understood as a lexical one than involving different compositional principles. Mandarin Chinese is generally assumed not to have perfect aspect. This means that the language cannot resort to (scope) means involving the perfect aspect to derive epistemic and metaphysical readings of non-root modals for the past. Rather, it employs back-shifting aspectual adverbs to obtain metaphysical modality for the past. In achieving this interpretation, the temporal shifting operator, in a sense, takes scope over the non-root modal. This is essentially similar to the perfect aspect scoping over the non-root modal in languages like English, German, and Italian. Hence, the difference between Mandarin Chinese and English-type languages lies in what morphologically realizes the temporal shifting operator to derive the metaphysical reading of non-root modals for the past: the perfect aspectual particle in English-type languages vs. aspectual adverbs like reng and hai in Mandarin Chinese. In addition, in both types of languages, the epistemic reading of non-root modals for the past involves no extra, costly mechanism (such as scope reversing and type shifting).

In spite of the similarities between Mandarin Chinese and English-type languages, the issues addressed in this paper are still interesting and important, both descriptively and theoretically. The discussion provides some empirical data and analytic insight into the question of how a language with a drastically different temporal system from many Indo-European languages expresses the ambiguity between epistemic and metaphysical readings of non-root modals for the past. Hopefully, the paper makes some useful 
contribution to the increasing understanding of cross-linguistic variation and universality, especially in the field of modality and its interaction with temporality.

\section{Endnotes}

"The terms "temporal perspective" and "temporal orientation" were coined by Condoravdi (2002). The temporal perspective of a modal is the time against which the modal is evaluated, and the temporal orientation is the temporal reference of the prejacent of the modal with relation to the temporal perspective.

${ }^{\mathrm{b}}$ By contrast, von Fintel and Gillies (2008) held that the temporal perspective of epistemic modals can be anchored toward the past. One of their examples is the sentence in i-b below, for which they argued that the temporal perspective of might is some time before the utterer of i-b looked into the drawer. In fact, it is rather controversial whether might in i-b is an epistemic modal, and if it is, whether it has a past temporal perspective. The interested reader can refer to Portner (2009), Hacquard (2011), and Abusch (2012) for related discussion. If might in i-b is an epistemic modal with a past temporal perspective, then I would have to say that English might differs from keneng in Mandarin Chinese. Keneng cannot be used as an epistemic modal in a similar fashion, as can be seen from the infelicity of the sentence in ii as a response to (the Mandarin Chinese equivalent of) i-a (cf., Chen 2012a, b).

(i) a: Why did you look into the drawer? The keys are not there, as you know now. b: But the keys might have been in the drawer.

(ii) \%但是钥匙可能在那个抽屉里。 danshi_yaoshi_keneng_zai__nei_ge_chouti_li. but_key_may/might_in_that_CL_drawer_inside Intended: But the keys might have been in the drawer.

${ }^{c}$ Please note that with the time adverbial yesterday immediately following the subject, $9 \mathrm{~b}$ sounds marginal to some speakers of (American) English.

${ }^{\mathrm{d}}$ Abbreviations used in this paper are: $\mathrm{LE}=$ Mandarin Chinese (perfective particle) $l e$, $\mathrm{DE}=$ Mandarin Chinese modification marker $d e, \mathrm{CL}=$ classifier, $\mathrm{PL}=$ plural marker, FUT = future, EMP = emphatic marker.

${ }^{\mathrm{e}}$ The different positions of shang xingqisan relative to keneng in the sentences in 12 may affect the information structure of the sentences, which I do not consider here. The important point here is that truth-conditionally, the three sentences in 12 are the same.

${ }^{\mathrm{f}}$ The claim also holds true when the temporal phrase denotes a future time. The sentence in i, adapted from comments by an anonymous reviewer, allows the temporal phrase 明天这个时候 mingtian zhe ge shihou 'this time tomorrow' to appear at the beginning of the sentence, right before keneng, or right after keneng, without affecting the meaning. The phrase specifies the time frame for evaluating the prejacent of the modal, and does not interact with the modal keneng.

(i) 张三明天这个时候可能 (已经) 到 (了) 北京。 zhangsan_mingtian_zhe_ge_shihou_keneng_(yijing)_dao_(le)_beijing. Zhangsan_tomorrow_this_CL_time_may/might_already_arrive_LE_Beijing. It is possible that Zhangsan will (have already) arrive(d) in Beijing this time tomorrow. 
${ }^{\mathrm{g}}$ In addition, all of the example sentences that Chen (2012b) used to argue for the existence of past temporal perspectives for epistemic keneng were answers to why questions. The choice is very likely not accidental. Stephenson (2007) posited that because can shift the temporal perspective of a modal. If the idea holds for Mandarin Chinese as well, another possible explanation is to attribute the back-shifting of temporal perspective to a covert because in Chen's example sentences. Due to space considerations, I will not delve into the detail of this possible explanation.

${ }^{\mathrm{h}} \mathrm{An}$ anonymous reviewer raised the question of whether contrastive contexts can make shifting of temporal perspective of epistemic keneng possible. He/she gave the example in i below. In my opinion, the two occurrences of keneng do not have the same modal flavor. The first keneng is a metaphysical modal, which I think is made acceptable in the clause by a covert aspectual adverb hai. The first clause in i describes the metaphysical possibility, valid during yesterday, for the speaker to make the relevant promise. If the first keneng was used epistemically, the first clause in i would be about the speaker's epistemic state about a (possible) event happening yesterday. Then one would expect that the first clause can be replaced with ii. However, inserting ii as the first clause in i would lead to unacceptability. By contrast, the second keneng is a true epistemic modal, and the last clause in i describes how the speaker perceives the possibility of her making a promise the next day, based on her epistemic state at the utterance time.

(i) 我昨天可能答应你, 今天还可以考虑, 明天, 就不可能了。 wo_zuotian_keneng_daying_ni, jintian_hai_keyi_kaolu, mingtian, jiu_bu_keneng_le. I_yesterday_may/might_promise_you, today_still_can_consider, tomorrow_EMP_not_possible_LE. It was possible yesterday for me to promise you, and I still can consider it today, but it is impossible (for me to consider it) tomorrow.

(ii) 我昨天可能 (已经) 答应了你。 wo_zuotian_keneng_(yijing)_daying_le_ni. I_yesterday_may/might_already_promise_LE_you I might have (already) promised you yesterday.

${ }^{\text {i }}$ Some may wonder whether the ungrammaticality of $16 \mathrm{a}-\mathrm{b}$ is due to the presence of the perfective marker le. Though eliminating le from them would make the two sentences somewhat more acceptable, they are still far away from being grammatical.

${ }^{j}$ The reader should note that reng has several other (related) uses. For example, it can be used, in the meaning of 'nevertheless, despite', to express disagreement or contrast. This use is illustrated in i below. Though some of those other uses of reng can co-occur with a non-root modal for the past, they do not license, or facilitate, a metaphysical interpretation for the modal. For related illustrations, the reader can refer to Ippolito 2007 for discussion of the various uses of still in English.

（i）尽管他有时候也吃垃圾食品, 他仍是我们的健康典范。 jinguan_ta_youshihou_ye_chi_lajishipin, ta_reng_shi_womende_jiankang_dianfan. although_he_sometimes_also_eat_junk food, he_still_be_our_health_example Although he also eats junk food occasionally, he is still our model of being healthy.

${ }^{\mathrm{k}}$ It should be noted here that even when a past-denoting temporal phrase appears immediately before reng/hai, the epistemic reading may still be available. That is, the 
temporal phrase may skip modifying reng/hai, and choose to modify the prejacent of the modal. My intuition is that in such cases, reng and hai mean "nevertheless, notwithstanding, which is different from its use as a temporal shifter.

${ }^{\mathrm{I}}$ The sentence in 24 could be made acceptable with a metaphysical reading, for instance, if the speaker uttered it in the middle of talking about how Zhangsan made himself well prepared the night before last. In this scenario, the time of preparation can be understood as the temporal perspective of keneng.

${ }^{\mathrm{m}}$ In fact, Lin (2006) treated the verb final le not purely as a perfective marker. In his semantic definition, he took the result state of the event into consideration, and proposed that the result state includes some time that either is bound in the linguistic context or can be derived from the context of use. The result state, if indeed present in the semantics of $l e$, is not relevant to the discussion in this paper. Hence, it is omitted in the definition given in 26.

${ }^{\mathrm{n}}$ I should further acknowledge that the definition of $l e$ in 26 has yet another simplification, which, however, does not affect the main, temporal shifting idea pursued in this paper. The definition assumes that the time of evaluation for $l e$ is anchored to the utterance time, and leaves aside cases where $l e$ is embedded under a temporal phrase or where it expresses a relative past. I thank an anonymous reviewer for pointing out this simplification.

${ }^{\circ}$ For the sake of convenience, I explicate the " $t_{\text {etop }}<t_{0}$ " requirement in 26 as a presupposition, rather than including it in the "core" definition of $l e$. Such a choice does not affect the overall argument in this paper.

${ }^{\mathrm{p}}$ As an anonymous reviewer correctly pointed out, the essence of my analysis does not depend on any particular form of LF or even whether there is LF, to begin with.

${ }^{\mathrm{q}}$ The assumption is adopted only for the sake of convenience. It only affects what the formal definition of reng looks like on the surface. Nothing in my analysis truly hinges on this assumption, as also pointed out by an anonymous reviewer.

${ }^{\mathrm{r}}$ In the literature on counterfactuality in Mandarin Chinese (e.g., Jiang 蒋严 2000, Yong 2013), little attention has been paid to counterfactual implicature induced by temporal back-shifting and associated quantificational domain widening. Nevertheless, it would take us too far afield to delve into the topic in the current paper.

${ }^{\mathrm{s}}$ In this respect, reng and hai are opposite of jiu. The latter can be used to indicate that a state has been going on continuously SINCE the associated reference time. As pointed out by an anonymous reviewer, jiu also can appear with non-root modals for the past, and may manifest different behaviors from reng and hai. I leave it to future research whether and how jiu affects the temporal properties of non-root modals.

Competing Interests

The author declares that he has no competing interests.

\section{Acknowledgements}

I would like to thank the three anonymous reviewers for all the helpful comments and suggestions, which have led to improvement at various places of the paper. My sincere gratitude also goes to the Editors of Lingua Sinica for their help with the paper. Needless to say, all remaining errors and inadequacies are my own. 
Chen, Sihwei. 2012a. The interaction of modals and temporal markings in Mandarin Chinese. In Proceedings of GLOW in Asia IX (poster sessions), ed. Nobu Goto, Koichi Otaki, Atsushi Sato, and Kensuke Takita, article 4. Mie, Japan: Mie, Japan: Mie University.

Chen, Sihwei. 2012b. The temporal interpretation of modals in Mandarin Chinese. In UBC Working Papers in Linguistics 34, ed. Alexis Black and Meagan Louie, 15-30. Vancouver: University of British Columbia.

Condoravdi, Cleo. 2002. Temporal interpretation of modals: Modals for the present and for the past. In The construction of meaning, ed. David I Beaver, Luis D Casillas Martínez, Brady Z Clark, and Stefan Kaufmann, 59-88. Stanford: CSLI Publications.

Hacquard, Valentine. 2006. Aspects of modality. Ph.D. dissertation. MIT.

Hacquard, Valentine. 2011. Modality. In Semantics: An international handbook of natural language meaning, ed. Claudia Maienborn, Klaus von Heusinger, and Paul Portne, 1484-1515. Berlin: Mouton de Gruyter.

Hu, Jianhua, Haihua Pan, and Liejiong Xu. 2001. Is there a finite vs. nonfinite distinction in Chinese? Linguistics 39(6): 1117-1148.

Huang, C-T James. 1982. Logical relations in Chinese and the theory of grammar. Ph.D. dissertation, MIT. Ippolito, Michela. 2007. On the meaning of some focus-sensitive particles. Natural Language Semantics 15(1): 1-34

Jiang, Yan 蒋严. 2000. The counterfactual interpretation of conditional sentences in Chinese 汉语条件句的违实解释. In Research and exploration in grammar, X 语法研究和探索 (十), ed. Mei Fang and Bojiang Zhang, 257-279. Beijing: The Commercial Press.

Klecha, Peter. 2012. Modal constraints on temporal reference. Paper presented at The $43^{\text {rd }}$ Annual Meeting of The North East Linguistic Society. City University of New York, October 2012.

Klein, Wolfgang, Ping Li, and Henriette Hendriks. 2000. Aspect and assertion in Mandarin Chinese. Natural Language and Linguistic Theory 18(4): 723-770.

Kratzer, Angelika. 1981. The notional category of modality. In Words, worlds, and contexts: New approaches to word semantics, ed. Hans-Jürgen Eikmeyer and Hannes Rieser, 38-74. Berlin and New York: Walter de Gruyter.

Kratzer, Angelika. 1991. Modality. In Semantics: An international handbook of contemporary research, ed. Arnim von Stechow and Dieter Wunderlich, 639-650. Berlin and New York: Walter de Gruyter.

Li, Charles N., R. McMillan Thompson, and Sandra A. Thompson. 1982. The discourse basis of the perfect aspect: The Mandarin Particle le. In Tense and aspect: Between semantics and pragmatics, ed. Paul J Hopper, 19-44. Amsterdam: John Benjamins.

Lin, Jo-wang. 2006. Time in a language without tense: The case of Chinese. Journal of Semantics 23(1): 1-53.

Michaelis, Laura. 1993. "Continuity" within three scalar models: The polysemy of adverbial still. Journal of Semantics 10(3): 193-237.

Mondadori, Fabrizio. 1978. Remarks on tense and mood: The perfect future. In Studies in formal semantics: Intensionality, temporality, negation, ed. Franz Guenthner and Christian Rohrer, 223-248. Amsterdam: North-Holland Publishing Company.

Portner, Paul. 2009. Modality. Oxford and New York: Oxford University Press.

Smith, Carlota. 1997. The parameter of aspect. Dordrecht: Kluwer Academic Publishers.

Soh, Hooi-ling. 2009. Speaker presupposition and Mandarin Chinese sentence-final le: A unified analysis of the "change of state" and the "contrary to expectation" reading. Natural Language and Linguistic Theory 27(3): 623-657.

Stephenson, Tamina. 2007. Toward a theory of subjective meaning. Ph.D. dissertation. MIT.

Stowell, Tim. 2004. Tense and modals. In The Syntax of time, ed. Jacqueline Guéron and Alexander Lecarme, 621-635. Cambridge, MA: MIT Press.

Tsai, W-T Dylan. 2001. On subject specificity and theory of syntax-semantics interface. Journal of East Asian Linguistics 10(2): 129-168.

von Fintel, Kai, and Anthony Gillies. 2008. CIA leaks. Philosophical Review 117(1): 77-98.

von Fintel, Kai, and Lisa Matthewson. 2008. Universals in semantics. The Linguistic Review 25(1): 49-111.

Xie, Zhiguo. 2011. Ambiguity in the 'non-root modal + perf' construction revisited. In Proceedings of the $28^{\text {th }}$ West Coast Conference on Formal Linguistics, ed. Mary Byram Washburn et al, 205-213. Somerville, MA: Cascadilla Proceedings Project.

Xie, Zhiguo. 2012. The modal uses of de and temporal shifting in Mandarin Chinese. Journal of East Asian Linguistics 21(4): 387-420

Xu, Liejiong. 1986. Towards a lexical-thematic theory of control. The Linguistic Review 5(4): 345-376.

Yong, Qian. 2013. Typological stage of counterfactuals in Chinese. In Proceedings of the $27^{\text {th }}$ Pacific Asia Conference on Language, Information, and Computation, ed. Department of English, 329-338. Taipei, Taiwan: National Chengchi University.

Yun, Jiwon. 2006. Tense, modals, and counterfactuality. Manuscript, Cornell University. 